\title{
Exploration of Vocational Skills Training for Applied Undergraduate Students
}

\author{
Fubin Shan \\ College of Finance and Trade,BoHai University, Jinzhou, P.R.China \\ 351581707@qq.com
}

Keywords: Applied undergraduate; Vocational skills; Training; Exploration

\begin{abstract}
The applied undergraduate education is a new form in China's modern higher education system, which is still in stage of exploration and development. Under concept of competency based, basic goal and purpose of training applied talents is vocational skills. Based on development of industry and actual work of enterprises, vocational skills were divided into four levels which are basic skills, special skills, comprehensive skills and innovative skills. According to characteristics of students and content of skill training, skill training program was designed. It includes school training system, practice education system, practice system, skill competition training system, skill certificate training system and innovation and entrepreneurship training system.

Applied Undergraduate Education is needed to meet needs of economic and social development. With four years of undergraduate education, students are trained to become high-level skilled talents. Vocational skills based on jobs are core of applied undergraduate education. It not only conforms to requirements and orientation of modern higher vocational education, but also conforms to characteristics of applied undergraduate students. This is an effective adaptation to changing needs of enterprises and development of the industry.
\end{abstract}

\section{Main Contents of Vocational Skills Training for Applied Undergraduate Students}

Based on analysis of vocational skill structure and level, content of vocational skill training for applied undergraduate students is determined according to fields and positions in which students are likely to be employed. Training contents can be divided into four aspects.

\section{Cultivation of Basic Skills}

The basic skills are skills are required by industries and enterprises in which students are employed. Foundational skills include basic knowledge, general techniques and routine skills which are needed to complete job. The purpose of training basic skills is to enable students to be qualified for a certain type of work and to be qualified for a vocational qualification certificate[1]. Through training, students can preliminarily recognize work of a certain kind of post. This lays foundation for completing work tasks.

\section{Cultivation of Specific Skills}

The specialized skills refer to technical skills for completing task. Specific skills include skills of operating equipment and instruments, solving routine problems and communicating with customers. The goal of training specific skills is to enable students to perform their duties well. Under dual guidance of enterprise personnel and school teachers, students can participate in actual work, so that they can gradually master various required skills.

\section{Cultivation of Comprehensive Skills}

Comprehensive skills refer to overall ability to complete job tasks. Comprehensive skills are integration of various specific skills. The purpose of developing students' comprehensive skills is to equip students with high-level and systematic skills to achieve good performance in work. After mastering comprehensive skills, students will be able to solve more complex practical tasks.

\section{Cultivation of Innovative Skills}

Creative ability refers to ability to use creative thinking to creatively solve problems in work. To cultivate innovative skills, students are expected to have good career prospects. Students participate 
in technological innovation projects and technological breakthrough projects, accomplish specific tasks to improve their innovation ability under guidance of teachers.

\section{Scheme Design of Vocational Skills Training for Applied Undergraduate Students}

The design of training scheme should follow goal and orientation of Application-oriented Undergraduate Talents training, and match characteristics and needs of students. More importantly, it should be in line with development trend of industry and employing needs of enterprises[2].

\section{Take Ability as Basic Training Goal}

Improving students' employability is an inevitable choice for application-oriented undergraduate students[3]. According to job position of students' future employment, determine objectives and content of vocational skills training after a comprehensive analysis of job content. Professional skills are divided into specific abilities. The each special ability includes four aspects related to post work: knowledge, attitude, experience and evaluation. Through training, students can have practical ability to engage in a certain post.

\section{Integration of Training Contents and Channels}

With professional skills as core, combine undergraduate education with skill training. Skills are divided into four levels. There are six methods of cultivation. Choose appropriate method in six ways according to content and characteristics of each level of skill training. Ensure that training objectives can be achieved.

\section{Set up Three Levels of Skill Standards}

According to attributes and requirements of students' future job positions, a standard system of vocational skills training including "three categories" is constructed. The three criteria are national standards, industry standards and enterprise standards. Training standards should be used as policy of cultivation work and criterion of evaluation work[4].

\section{Establishing a Developmental Assessment System}

Following concept of developmental education and oriented by practical needs of enterprises and students' sustainable development needs. Following concept of developmental education, a developmental skill assessment system is set taking actual needs of enterprises and needs of students' sustainable development as guidance[5]. The assessment system includes feedback, basis, method, content and assessment of result.

\section{Innovative Curriculum System}

Based on characteristics and training objectives of application-oriented undergraduate students, course system is innovatively constructed in process of skill training. The curriculum is divided into special skills courses, comprehensive skills courses and innovative skills courses according to level of skills. Different types of courses have different training modes, assessment methods and teaching staff.

\section{Participation of Pluralistic Subjects}

Setting up off campus practice education bases and practice bases which is based on enterprises, through cooperation between schools and enterprises. Students should make full use of equipment and facilities in production line to improve their vocational skills. This can ensure that skills can meet actual requirements of enterprises. Cooperate with other colleges and universities in region to make use of their teaching resources, cooperate with industry association and regional education administration departments to listen to their opinions and suggestions, so as to make skills training more scientific and reasonable[6]. This makes skills training more scientific and reasonable.

\section{Dual Directed Teacher System}

The teacher system covers theoretical instructors and practical instructors. These instructors come from schools, other institutions, enterprises, and industry organizations. Combined with requirements of skill training, teachers should be trained in a targeted way. The guidance teachers from universities should be trained regularly in enterprises. The instructors who come from enterprise and industry organization should study in university. 


\section{Approaches to Cultivation of Professional Skills for Applied Undergraduates}

\section{Practical Training System in School: Cognition and Orientation of Skills}

The training system in school includes laboratory, training base, training standards, training content, training courses, training assessment and reward. The basic skills training should be carried out in which. Project-based patterns can be used to develop skills. The skills are divided into several modules and each module is designed as a work item. Each work item is training content and assigned to students. Students use methods and techniques which is commonly used in enterprise to complete task, so as to master preliminary skills needed for job.

\section{Practical Training System in Enterprise: Imitation and Integration of Skills}

Choose suitable enterprises and build a practical education base with universities. It includes organization, training mode, teaching staff, curriculum system, safeguard measures and so on. The practice bases in enterprises play different roles in different stages. In the base, students follow designated staff to complete their daily work, so gradually grasp specific skills in imitation. Students can also participate in more complicated work and master comprehensive skills required by job[7].

\section{Internship System in Enterprises: Proficiency and Application of Skills}

Build internship system, relying on practical education base in enterprise. The position, contents, guidance teachers and assessment criteria of internship should be determined jointly by schools and enterprises in which. Internship is to enable students to master skills more proficient through application in work. Students finish their daily tasks and solve problems in practical work. In this way, students' vocational skills are further improved and improved. Through practice, students gradually grow up to be a laborer who meets requirements of enterprises.

\section{Training System about Skills Competition: Training and Promotion of Skills}

Professional skills competition is a comprehensive application and display of vocational skills. It is also training and upgrading about theory, skills and professionalism. The system includes competitions, training questions, classified students, instructors, training methods and so on. Using skill competitions can effectively improve students' basic skills, special skills and comprehensive skills. In practice, students in different specialties should take part in corresponding competitions. At the same time, all students have to take part in skills competition to ensure universality of skill training.

Training System for Obtaining Vocational Skills Certificate: Identification and Distinction of Skills

According to relevant national policies and industry requirements, training system for obtaining vocational skills certificates should be established[8]. The system includes test questions, theory and knowledge courses, skills training guidance courses, etc. The certificate is divided into professional qualification certificate and skill level certificate, so training should also correspond to it. Teachers and enterprise technicians serve as guidance teachers to guide students to take exams.

\section{Training System about Entrepreneurship: Innovation and Application of Skills}

Combined with school's innovation and entrepreneurship education, training system for students' entrepreneurship should be established. The system includes laboratories, entrepreneurial bases, entrepreneurial training programs and guidance teachers. Students who have entrepreneurial intention to start their own business in campus entrepreneurial practice base. The students' entrepreneurship is tracked and guided by teachers and enterprise experts.

\section{Practical Requirements of Vocational Skills Training for Applied Undergraduate Students}

\section{Practicality and Effectiveness of Skill Training}

Application-oriented Education focuses on developing students' applied skills for future work, so design of training system should simulate actual work of the enterprise and training process should be guided by actual work of enterprise[9]. In practice, technical personnel, management personnel and production personnel should be invited to participate in training. 


\section{Directivity and Pertinence of Skill Training}

Based on trend of industry development and demand of enterprises for talents, employment is taken as orientation of vocational skill training. Adjust content and method of cultivation according to change in enterprise needs. In design of training process, design of course system, design of guiding work, design of skills assessment and other links, enterprise should be fully and comprehensively involved. In this way, students can master skills to adapt to specific work, so students can be competent after graduation.

\section{Gradation and Continuity of Skill Training}

Vocational skills are divided into different levels, corresponding level of skills as focus of training in different stages of student training. In freshmen and sophomores of university, various special skills are focus of training through in school training and enterprise training[10]. In junior year of university, special skills and comprehensive skills are focus of training using enterprise training, skills competition, certificate examination and other means. In fourth year of college, training focuses on comprehensive skills and entrepreneurial skills through internship and entrepreneurship training.

\section{Summary}

There are four levels of vocational skills training for applied undergraduate students. Which are basic skills, special skills, comprehensive skills and innovative skills. The core of design training plan is to cultivate students' ability to fulfill their duties. The training program includes objectives, contents, standards, assessment, curriculum, subjects, and faculty system.

\section{Reference}

[1] Information on http://www.haedu.gov.cn.

[2] Gu Kaihui, Sun Xiaobing, Guo Xiu Zhen. Application Oriented Undergraduate Education Integrated into Vocational Skills. Physical Experiment of College,126 (2017)124-126.

[3] Wang Haizhou, Liang Yan. On Cultivation of Professional Ability of Applied Undergraduate Talents in Local Universities. Education and Vocation,793(2014) 80-82.

[4]Chen Peihong, Wang Zhong, Yuan Jian. Practical Exploration of "4+0" Applied Undergraduate Training Mode. Journal of Nantong Vocational \& Technical Shipping College,63(2018)81-83.

[5] Xiao Lufei, Meng Fei, Xie Xiaohua, Chen Jing. Dilemma and Thinking of Linking up Skilled Talents with Applied Talents. Journal of Chaohu College,147(2017) 146-150.

[6] Li Kun, Du Lichun, Li Guifeng. Orientation of Talents in Local Universities Should be Professionalized. University Education, 94(2018) 28-30.

[7] Liu Yun, Yuan Xiping, Zhang Yuhua. Theory and Practice of Connotation Construction of Applied Undergraduate Education -- Taking Kunming University of Science and Technology City College as an Example. Journal of Kunming University of Science and Technology(Social Science),107(2018)71-79.

[8] Zhang Jiao, Chung Yue. Necessity of Introducing "Double Certificate" System in Application Oriented Universities. Higher Vocational Education(Journal of Tianjin Vocational Institute), 132( 2017) 7-10.

[9] Gao Jing. Connotation, Development Basis and Realization Mode of Applied Undergraduate Education .Education and Vocation,870(2016) 12-15.

[10] Information on http://www.sohu.com. 